\title{
Moving from 5G in Verticals to Sustainable 6G: Business, Regulatory and Technical Research Prospects
}

\author{
Marja Matinmikko-Blue ${ }^{1[0000-0002-0094-6344]}$, Seppo Yrjölä2[0000-0003-2053-9700], and Petri \\ Ahokangas $^{3[0000-0002-2351-8473]}$ \\ ${ }^{1}$ Centre for Wireless Communications, University of Oulu, Finland \\ ${ }^{2}$ University of Oulu, Finland and Nokia, Finland \\ ${ }^{3}$ Oulu Business School, Martti Ahtisaari Institute, University of Oulu, Finland \\ marja.matinmikko@oulu.fi
}

\begin{abstract}
Mobile communication research is increasingly addressing the use of $5 \mathrm{G}$ in verticals, which has led to the emergence of local and often private $5 \mathrm{G}$ networks. At the same time, research on $6 \mathrm{G}$ has started, with a bold goal of building a strong linkage between $6 \mathrm{G}$ and the United Nations Sustainable Development Goals (UN SDGs). Both of these developments call for a highly multi-disciplinary approach covering the inter-related perspectives of business, regulation and technology. This paper summarizes recent advances in using $5 \mathrm{G}$ to serve vertical sectors' needs and describes a path towards sustainable $6 \mathrm{G}$ considering business, regulation and technology viewpoints. By focusing on key trends, the research summarizes four alternative scenarios for the futures business of $6 \mathrm{G}$ and considers related regulatory and technology aspects. Our findings highlight the importance of understanding the complex relations of business, regulation and technology perspectives and the role of ecosystems in both $5 \mathrm{G}$ in verticals and ultimately in the development of sustainable $6 \mathrm{G}$ to bring together stakeholders to solve long-term sustainability problems.
\end{abstract}

Keywords: Business Strategy, Regulation, Scenario Planning, Sustainability, $5 \mathrm{G}, 6 \mathrm{G}$.

\section{Introduction}

5G deployments are underway in the global scale with the first applications focusing on offering high capacity mobile broadband services. The promise of $5 \mathrm{G}$ to boost the digitalization of various vertical industries is gradually gaining increasing attention and the emergence of local 5G networks [Matinmikko et al. 2017; Matinmikko et al. 2018] is starting to take place in some countries. Local $5 \mathrm{G}$ networks allow different stakeholders to use their own local connectivity platforms without having to rely on mobile network operators. These developments are occurring in complex multi-stakeholder ecosystems where regulatory, business, and technical perspectives are highly intertwined. The emergence of using $5 \mathrm{G}$ in the various verticals brings together the ICT sector and the vertical sector in question with their own structures and rules for operations, calling for an ecosystem-level focus. Especially, the availability of spectrum for 
local networks fully depends on the country of operations, emphasizing the importance of regulatory decisions.

At the same time, research on the sixth generation $(6 \mathrm{G})$ of mobile communication networks has started globally aiming at first deployments in the 2030s. The first $6 \mathrm{G}$ White Paper published in 2019 presented a joint 6G research vision as a group work of 70 experts globally [Latva-aho \& Leppänen, 2019]. The paper depicted the future 6G networks as an intelligent system of systems that combines the communication services with a set of other services including imaging, sensing, and locationing services, opening a myriad of new application areas. A set of continuation 6G White Papers published in 2020 [6G Flagship White Papers 2020] prepared in collaboration with 250 international experts went more into details and presented e.g. alternative future scenarios for the business of 6G [Yrjölä et al., 2020], and developed a tight linking between $6 \mathrm{G}$ and the United Nations Sustainable Development Goals (UN SDGs) [Matinmikko-Blue et al., 2020a]. Some of the developed future $6 \mathrm{G}$ business scenarios have taken sustainability as the starting point, stressing that the whole development of the future mobile communication networks should aim at helping society at large in its attempts to meet the sustainable development goals [Latva-aho \& Leppänen 2019; Yrjölä et al. 2020a; Yrjölä et al. 2020b; Matinmikko-Blue et al. 2020a].

To make sense of moving from $5 \mathrm{G}$ in verticals towards $6 \mathrm{G}$, we must envision future 6G systems targeting 2030 holistically from the perspective of the interaction between business, regulation and technology perspectives in envisioning future research prospects. The alternative futures of $6 \mathrm{G}$ will be shaped by growing societal requirements like inclusivity, sustainability, resilience, and transparency - a highly complex area that will call for major changes in industrialized societies in the long run, see [Latva-aho et al. 2019; Matinmikko-Blue et al. 2020a]. The business perspective specifically needs to consider sustainability [Kuhlman \& Farrington, 2010; Evans et al. 2017] in a way that combines the economic (e.g., profit, business stability, financial resilience, viability), societal (e.g., individuals', communities', regulative values) and environmental (e.g., renewables, low emissions, low waste, biodiversity, pollution prevention) perspectives. As an emerging field, 6G business scenarios and strategies have not been widely discussed in the literature to date. However, vision papers on future communication needs, enabling technologies, the role of artificial intelligence (AI), and emerging applications have recently been published [Viswanathan \& Mogensen, 2020; Saad, Bennis \& Chen, 2019; Letaief et al. 2019]. Furthermore, discussion has latterly expanded to 6G indicators of value and performance [Ziegler \& Yrjölä, 2020], the role of regulation and spectrum sharing [Matinmikko-Blue et al., 2020a], the antecedents of multi-sided transactional platforms [Yrjölä, 2020], antecedents of the 6G ecosystem [Ahokangas et al. 2020a] and the exploratory scenarios of $6 \mathrm{G}$ business [Yrjölä et al., 2020].

Building on the above discussion, this paper provides an overview of $5 \mathrm{G}$ in verticals towards sustainable 6G from business, regulation and technology perspectives and presents related research prospects. The paper summarizes future scenarios for sustainable 6G business strategies in the timeframe 2030-2035, originally documented in [Yrjölä et al., 2020], and related strategic options. The rest of this paper is organized as follows. Chapter 2 summarizes the state of the art of $5 \mathrm{G}$ in verticals from business, regulation 
and technology perspectives. Chapter 3 presents an overview of sustainable 6G. Future business scenarios for sustainable $6 \mathrm{G}$ and related strategic options are presented in Chapter 4. Finally, future outlook and conclusions are provided in Chapter 5.

\section{State of the Art of 5 G in Verticals}

5G has been set high in national agendas to speed up digitalization of various sectors of society in many countries. This chapter presents recent developments in the use of $5 \mathrm{G}$ networks to serve the needs of different vertical sectors, such as industry, energy, and health, and their public sector counterparts, from the interrelated business, technology and regulation perspectives.

\subsection{Business Perspective}

Business perspective plays an important role in understanding the opportunities that a new technology can offer. The identification of the opportunity space for $5 \mathrm{G}$ business in verticals requires discussing four inter-related key themes: 1) the convergence of connectivity and data platforms and related ecosystems, 2) enablers, barriers and limitations to scalability and replicability of 5G solutions and business models, 3) legitimation of the new roles and business models within the verticals, and the 4) economic, societal and environmental sustainability of $5 \mathrm{G}$ solutions and business models. As vertical 5G networks are often considered as local networks, the platform-based business models utilized by different stakeholders face several challenges related to the aforementioned themes.

Mobile communication networks have for long been seen as platforms [Pujol et al, 2016] or ecosystems [Basole and Karla, 2011]. However, with the deployment of 5G networks, the mobile connectivity platforms operated by mobile network operators (MNOs) are increasingly becoming converged with the data platforms of various cloud service providers, giving rise to novel kinds of platform ecosystems. In industry verticals also the Industry 4.0 platforms as a specific type of data platforms play an important role. Extant literature identifies centralized, hybrid and fragmented types of converged connectivity and data platforms for industry verticals [Ahokangas et al., 2020b]. In this kind of vertical context, a key feature of the converged platforms is the degree of openness achieved for different stakeholders of the ecosystem. Related to openness, the complexity, complementarity and interdependence of the converged connectivity and data platforms can be clarified by looking at the various components, interfaces, data and algorithms utilized in these platforms [Yrjölä et al., 2019] in connection to the connectivity ( $5 \mathrm{G}$ or other), content (e.g., information or data), context (location- or use-case specific data) or commerce (offering made available via a platform) business models utilized [Iivari, et al., 2020]. The vertical business model for local 5G operators presented by [Ahokangas et al., 2019] builds specifically on the idea to provide tailored end-to-end services in restricted geographical areas, such as industry sites, to the users locally. Vertical business models form a vertically structured ecosystem around the activity. The presented oblique business model and corresponding oblique 
ecosystem in turn builds on mass-tailored end-to-end services with stricter requirement for segmentation [Ahokangas et al., 2019].

The different types of converged connectivity and data platforms and the business models identified for them have varying potential for scalability and replicability. A scalable business model is agile and provides exponentially increasing returns to scale in terms of growth from additional resources applied [Nielsen and Lund, 2018], whereas a replicable business model can be copied to several markets simultaneously with minimum variations [Aspara et al., 2010]. For a firm running a vertical business model, scalability is based on the firm's capability to understand customer-specific needs and fulfill them, but limited on the size of the cases, their volume and timeline. For a firm running an oblique business model, scalability is based on the volume of unmet local needs and limited by access and availability of local infrastructures needed for providing the service [Ahokangas et al., 2019].

Within converged connectivity and data platform ecosystems, different stakeholders have varying roles and can act as service providers. This raises the issue of legitimacy, meaning that the activities of the stakeholder providing the service is legal and fits with the institutionalized practices within the industry in question [Marano et al., 2020]. Achieving legitimacy for local vertical-specific 5G services and service providers through the deployment of local $5 \mathrm{G}$ networks is, however, an open question in many countries. Indeed, disruptive innovations such as $5 \mathrm{G}$ have been found to cause regulatory, incumbent and social "pushbacks" and they can be expected also for vertical 5G services, as legitimacy is a precondition for successful value creation and capture on a technology [Biloslavo et al., 2020].

The above discussion points out several challenges for reaching sustainable business models in $5 \mathrm{G}$ verticals. "A business model for sustainability helps describing, analyzing, managing and communicating (i) a company's sustainable value proposition to its customers, and all other stakeholders, (ii) how it creates and delivers this value, (iii) and how it captures economic value while maintaining or regenerating natural, social, and economic capital beyond its organizational boundaries" [Schaltegger et al., 2016, p. 6]. Building vertical $5 \mathrm{G}$ business opportunities calls thus for filling in the requirements of scalability, replicability, and sustainability in a legitimate way in a platform ecosystem comprising connectivity and data services.

\subsection{Regulation Perspective}

The serving of the different verticals with $5 \mathrm{G}$ networks is not only addressed by the current MNOs but increasing attention is being paid to local and often private $5 \mathrm{G}$ networks [Matinmikko et al. 2017; Matinmikko et al., 2018] that can be operated independent of the MNOs. Their emergence is highly dependent on the regulations that govern both the electronic communications market as well as the specific verticals, leading to a complex environment to operate. Regulations at national, regional and international levels define the operational conditions and there is wide variation between the national approaches but also some level of harmonization such as on the spectrum for $5 \mathrm{G}$. 
Prior work on regulatory developments on local $5 \mathrm{G}$ networks [Matinmikko et al., 2018; Vuojala et al., 2019; Lemstra, 2018; Ahokangas et al., 2020b] have considered access regulation, pricing regulation, competition regulation, privacy and data protection, and authorization of networks and services. Especially, the authorization of networks and services defining the ways how rights to use radio frequencies are granted is critical for the establishment of local private $5 \mathrm{G}$ networks. Without the timely availability of sufficient amount of spectrum suitable for operations in the given environment, it is not possible to deploy the local networks. Specific spectrum options for local 5G networks are analyzed in detail in [Vuojala et al., 2019] including unlicensed access, secondary licensing, spectrum trading/leasing, virtual network or local licensing. Local licensing has emerged as a new spectrum access model in $5 \mathrm{G}$ to allow different stakeholders to deploy local networks in addition to the MNOs. A study on the recent $5 \mathrm{G}$ spectrum awards decisions in the $3.5 \mathrm{GHz}$ band presented in [Matinmikko-Blue et al., 2019] shows that there is a big divergence in the spectrum awards by different countries taken by the regulators globally.

5G regulatory situation in Europe is discussed in [Lemstra, 2018] where two contrasting scenarios for the future telecommunication market are presented including evolutionary and revolutionary scenarios. Evolutionary scenario continues the MNO market dominance which is likely to occur under the current European regulatory framework. The revolutionary scenario introduces new virtual MNOs that serve specific industry sectors which calls for additional policy and regulatory measures. The mobile communication market is in a turning point with the emergence of locally operated $5 \mathrm{G}$ networks by different stakeholders, especially aiming at serving the verticals' specialized local needs.

\subsection{Technology Perspective}

Previous generation mobile technologies have been largely deployed by national (or multi-national) incumbent MNOs for public use, given the high levels of investments required for the infrastructure, and to acquire exclusive radio spectrum. Furthermore, management and operational costs of the networks have been significant, and mobile technologies have required large and complex system integration from global infrastructure vendors with specialized capabilities. In addition to improved performance characteristics in capacity, speed and latency, novel 5G architecture is bringing additional flexibility for traditional MNOs as well as local operators in system deployments. Key technologies expected to transform $5 \mathrm{G}$ for verticals include localization and decomposition of network functions, software defined networking and network virtualization among others [Morgado et al., 2018].

A critical aspect of the local private industrial $5 \mathrm{G}$ networks is the ability to create customized network slices, where instances of virtual network resources and applications can be delivered to a new breed of services tailored to specific customer or tenant needs with service level agreed performance on demand. Furthermore, the softwarebased network architecture enables efficient sharing of common network infrastructure and resource by different tenants. Abstracting the slice functionality through open interfaces exposure to third party service provisioning enables service-dominant model 
for the connectivity and underlying network resources, e.g., computing, data and intelligence. The evolution towards the cloud-native infrastructure abstraction both on core and radio access empowers technology vendors and service providers to deploy and operate flexible and portable processes and applications in dynamic multi-vendor cloud environments. The cloud embedded in the edge of the network provides tools for optimized performance and economics for both the virtualized network functions and any other performance critical enterprise or vertical service and can become a control point of the local connectivity and intelligence. Edge cloud use cases considered in $5 \mathrm{G}$ are e.g., cloud radio access network (Open RAN, Virtual RAN), edge security, network and service automation enhancing the network itself, and industrial automation, massive scale Internet of Things (IoT), and augmented intelligence with augmented reality (AR)/virtual reality (VR). Another critical aspect is the spectrum. Operations in higher carrier frequencies represent a challenge in terms of deployment. The availability of suitable spectrum for serving the verticals cannot be based on dedicated spectrum paradigm but requires sharing in different domains.

Figure 1 summarizes the presented business, regulation and technology perspectives for $5 \mathrm{G}$ in verticals.

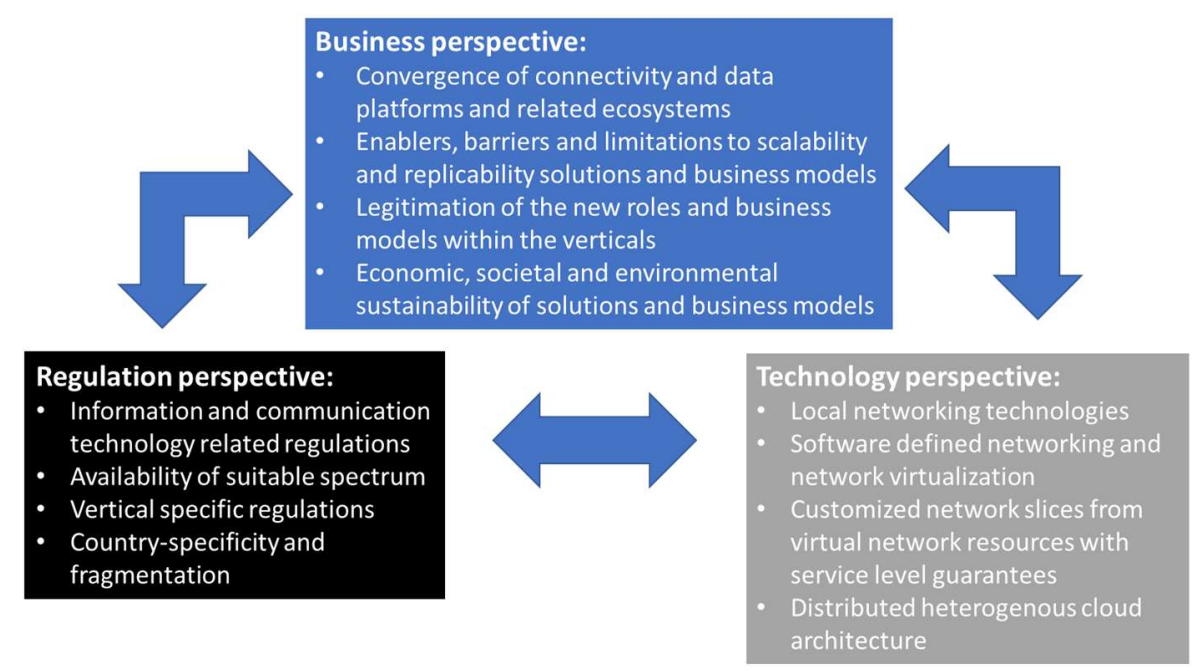

Fig. 1. Business, regulation and technology perspectives for $5 \mathrm{G}$ in verticals.

\section{Towards Sustainable 6G}

In parallel with the on-going development and deployment of $5 \mathrm{G}$ in verticals, research on the next generation, namely $6 \mathrm{G}$, systems has already started in different parts of the world, see [Latva-aho \& Leppänen, 2019] and [6G Flagship White Papers, 2020]. The research on 6G [Latva-aho \& Leppänen, 2019; Matinmikko-Blue et al., 2020a] has 
identified sustainability stemming from the UN SDGs as the starting point, and it needs to address the technical, business and regulation perspectives, which are discussed next.

\subsection{Role of UN SDGs in 6G}

Future 6G networks are aiming at first deployments around the year 2030 which is also the target year for the achievement of the UN SDGs. While $6 \mathrm{G}$ communications is expected to boost global growth and productivity, create new business models and transform many aspects of society, its linking with the UN SDGs needs to be clearly formulated. The starting point of $6 \mathrm{G}$ research vision presented in [Latva-aho \& Leppänen 2019] is that the development of $6 \mathrm{G}$ should be fully aligned with the UN SDGs [United Nations, 2018]. In a follow-up white paper, Matinmikko-Blue et al. [2020a] have developed a novel linking between 6G and the UN SDGs through the indicators of the UN SDG framework.

In [Matinmikko-Blue et al., 2020a] a three-fold role is foreseen for $6 \mathrm{G}$ as 1) provider of services to help reaching the UN SDGs, 2) enabler of measuring tools for data collection to help with the reporting of indicators, and 3) reinforcer of a new ecosystem to be developed in line with the UN SDGs. The white paper further details the linking between $6 \mathrm{G}$ and UN SDGs trough the existing indicators of the UN SDG framework where only 7 out of the 231 individual indicators are identified as being related to ICT. In reality, the ICT sector can influence many of the indicators, if not all. The white paper [Matinmikko-Blue et al., 2020a] analyses what 6G can do to contribute to the different UN targets within the SDG framework via the existing UN SDG indicators. The white paper proceeds to stating the need for a new set of indicators for $6 \mathrm{G}$, characterizing the three-fold role of 6G. Additionally, a preliminary action plan is presented, calling for research and educational organizations, governments, standards developers, users, MNOs, network equipment manufacturers, application and service providers and verticals to think out-of-the box and create new technology solutions and collaborative business models to develop new operational models that support the achievement of the SDGs which may need changes to the existing regulations.

\subsection{Business, Regulation and Technology Perspectives}

The discussion on $5 \mathrm{G}$ business perspective for deployment in verticals presented in Section 2.1 proposed to focus on business models as a way of thinking future $6 \mathrm{G}$ ecosystem stakeholders' choices regarding opportunities, value-add and capabilities, and their expected consequences as scalability, replicability, and sustainability. With the right business choices, opportunities will be identified related to novel and unmet needs, new types of customer and service provider, as well as the interfacing of humans with machines in $6 \mathrm{G}$. New value-add is seen to come from real-time and trustworthy communications, the use of local data and intelligence, and the commoditization of $6 \mathrm{G}$ resources as its competitive advantages, including extreme capacity and security, transaction and innovation platformization, and ubiquitous access. The expected business consequences of scalability may be related to the long tail of services, dataflow architecture, automation, and open collaboration between stakeholders; in terms of replicability, to deliberately design modularity and complementarity within platforms; and in 
terms of sustainability, to empower users and communities, and the utilization of sharing economic mechanisms in the markets.

Overall, governments and industries are under high pressure from the sustainability targets arising from the UN SDGs to renew their operations and the achievement of the goals provides new business opportunities especially for ICT solutions. These data and connectivity solutions can significantly contribute to industries to improve their resource efficiency and reduce waste but the solutions themselves need to be developed in alignment with the sustainability goals as well.

Digital convergence across industries and multi-level 6G platforms and ecosystems are creating a complex strategic environment that can lead to incomparable and distinct opportunities, as well as emergent problems. The regulations governing the use of future telecommunication systems and the relevant industry specific regulations together create a complex environment, especially around the use of data and connectivity platforms for different purposes. In particular, unanswered questions remain about ecosystemic business models in the context of sustainability. According to our recent findings [Yrjölä et al., 2020a; Yrjölä et al., 2020b], business ecosystems that aim to bring together stakeholders to solve systemic sustainability problems will require open ecosystem-focused value configuration and decentralized power configuration, where traditional stakeholder roles change, and new roles emerge. The focus needs to be on the long tail of specialized user requirements that crosses a variety of industries where related needs can be met with different resource configurations.

Spectrum continues to be the key resource for $6 \mathrm{G}$ systems as for any wireless networks throughout the times, and the availability of suitable spectrum continues to be significantly restricted due to the existing incumbent spectrum usage, see [MatinmikkoBlue et al. 2020b]. Spectrum availability is a good example of the complex relations of business, regulation and technology perspectives. The availability of spectrum is a regulation decision, which defines the business opportunities and yet is restricted with technical aspects. Potential operations of future $6 \mathrm{G}$ systems in the new higher frequency bands at upper millimeterwaves $(\mathrm{mmW})$ and terahertz $(\mathrm{THz})$ regions pose significant technical, regulatory and deployment related challenges. Therefore, future $6 \mathrm{G}$ is not restricted only to higher frequency bands but can also be used in the existing bands for mobile communications. What are the economically feasible operational models, how to protect existing incumbent users of the feasible bands and how to implement $\mathrm{THz}$ radio links continue to be open topics for $6 \mathrm{G}$.

The technology vision work in the global scale for systems towards 2030 and beyond has started at the International Telecommunication Union Radiocommunication sector (ITU-R) with the development of a report on future technology trends. The need for new indicators to characterize the performance of future $6 \mathrm{G}$ networks is evident [Latvaaho \& Leppänen, 2019; Matinmikko-Blue et al., 2020a; Pouttu et al., 2020], especially for defining and measuring resource efficiency and particularly energy efficiency. Also, the network architecture of $6 \mathrm{G}$ needs to be re-thought from prior generations of networks, see [Taleb et al., 2020]. Figure 2 provides a summary emphasizing the need to develop sustainable $6 \mathrm{G}$ in line with the UN SDGs from business, regulation and technology perspectives. 


\section{Development of sustainable 6G}

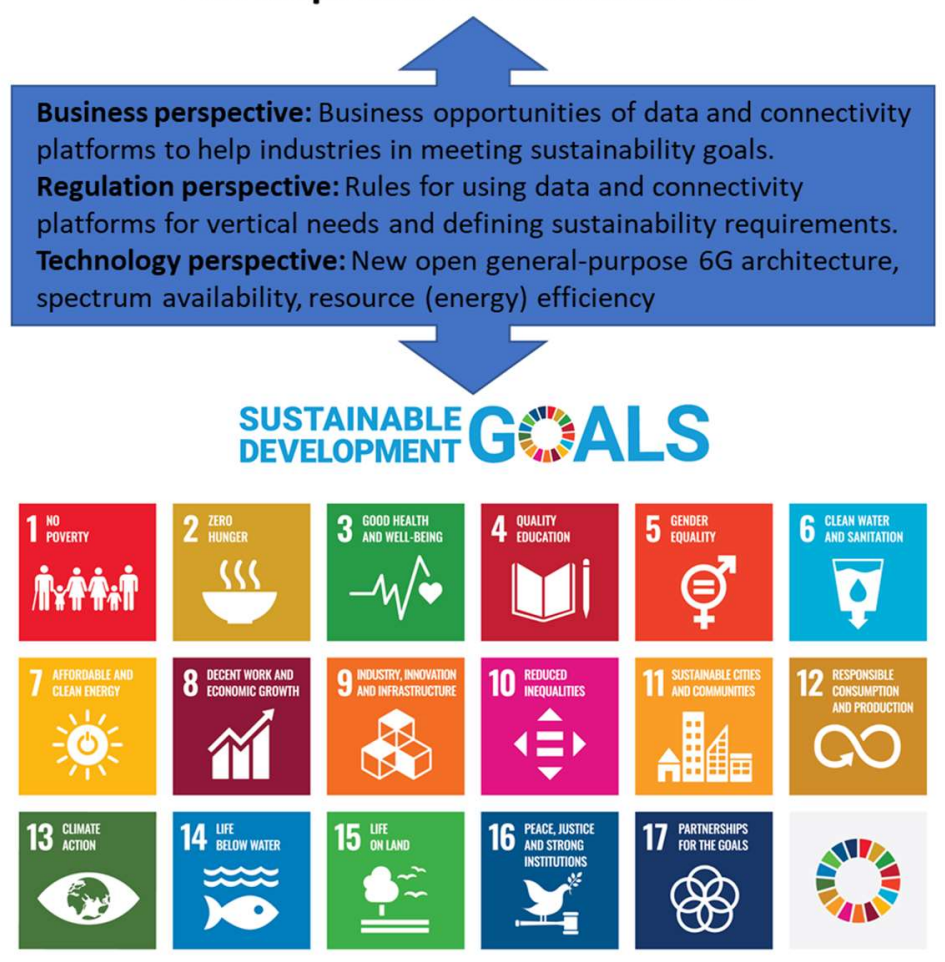

Fig. 2. Business, regulation and technology perspectives for sustainable development of $6 \mathrm{G}$.

\section{Business Scenarios and Strategic Options for 6G}

Next, we proceed to new business scenarios developed for $6 \mathrm{G}$ and related strategic options developed through a set of virtual future-oriented white paper expert group workshops organized by 6G Flagship at the University of Oulu in 2020 and documented and analyzed in [Yrjölä et al., 2020a; Yrjölä et al., 2020b].

\subsection{Methodology}

The alternative scenarios for the future business of $6 \mathrm{G}$ summarized in this paper were created using anticipatory action learning (AAL) research method [Stevenson, 2012] within 6G Flagship's white paper preparation [6G Flagship 2020]. The process involved a series of online workshops in January-April 2020 where a group of experts from research, standardization and development, telecommunication industry, government, and verticals joined to collaboratively create future business scenarios for $6 \mathrm{G}$. 
First, the key change drivers for future 6G business were identified resulting in 153 forces [Yrjölä et al, 2020a]. Using these drivers, a set of dimensions and endpoints were selected to form the basis for the scenario development as shown in Figure 3. Value creation and value configuration were selected as the main business dimensions with different end points emphasizing closed and open alternatives.

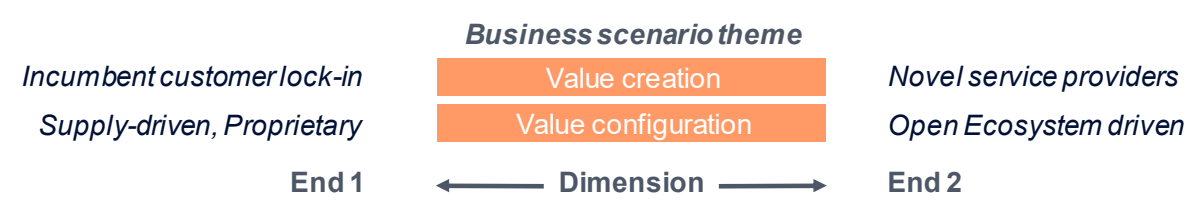

Fig. 3. Selected business scenario logic and dimensions.

We also used a simple rules strategy framework presented in [Eisenhardt \& Sull, 2001], which is a strategic management tool to develop strategies around identified business opportunities and describing the main processes. It provides a highly practical approach with guidelines in the following six rule categories introduced in [Eisenhardt \& Sull, 2001] and applied in the mobile communication market in [Ahokangas et al., 2013]: 1) Nature of opportunity rules, 2) How to conduct business and processes in a unique way, 3) Boundary rules to decide, which opportunities to pursue, 4) Priority rules to identify and rank the opportunities, 5) Timing rules to synchronize emerging opportunities and other parts of the company, and 6) Exit rules to selecting things to be ended.

Next, we introduce the four developed business scenarios using the dimensions of Figure 3 including Sustainable edge, Telco brokers, MNO6.0 and Over-the-top, as summarized in Figure 4, and presented in [Yrjölä et al., 2020a]. We also briefly summarize strategies as simple rules that were created for the most plausible MNO6.0 scenario and the most preferred Sustainable edge scenario.

\subsection{G Business Scenarios}

A set of business scenarios were developed in 6G Flagship's white paper process in 2020, documented in [Yrjölä et al. 2020a] and summarized in the follows. Figure 4 summarizes the developed four business scenarios following the scenario logic of Figure 3 .

In the first scenario, the Sustainable Edge Value Creation, scenario in the upper-right corner of Figure 4, the value creation is customer attraction-driven, and the value configuration is open ecosystem-focused. This scenario is built on decentralized open value configuration and ecosystem-driven business models where novel stakeholders take over customer ownership and networks. Changing stakeholder roles include webscales, over the top (OTT) companies and device vendors being responsible for business to consumer (B2C) customers and local private cloud native networks serve business to business (B2B) customers. The role of traditional MNOs has changed into a wholesale connectivity service provider. Open source principles have become widely spread 
leading to technology and innovation ownership beyond traditional technology providers through open application programming interfaces (API) and novel resource brokerage. This scenario includes new stakeholder roles also in the form of local communities and special interest groups operating various edge resources in specific locations, such as campuses and remote areas to promote local innovation. New applications come with $6 \mathrm{G}$ technology that act as digital value platforms expanding our experiences towards digital computer-generated virtual worlds. The current focus on global-scale solutions changes towards local solutions that balance local demand with local supply and support circular economies. Especially the manufacturing vertical will move towards local decentralized manufacturing supporting a new crowdsourcing-based production ecosystem.

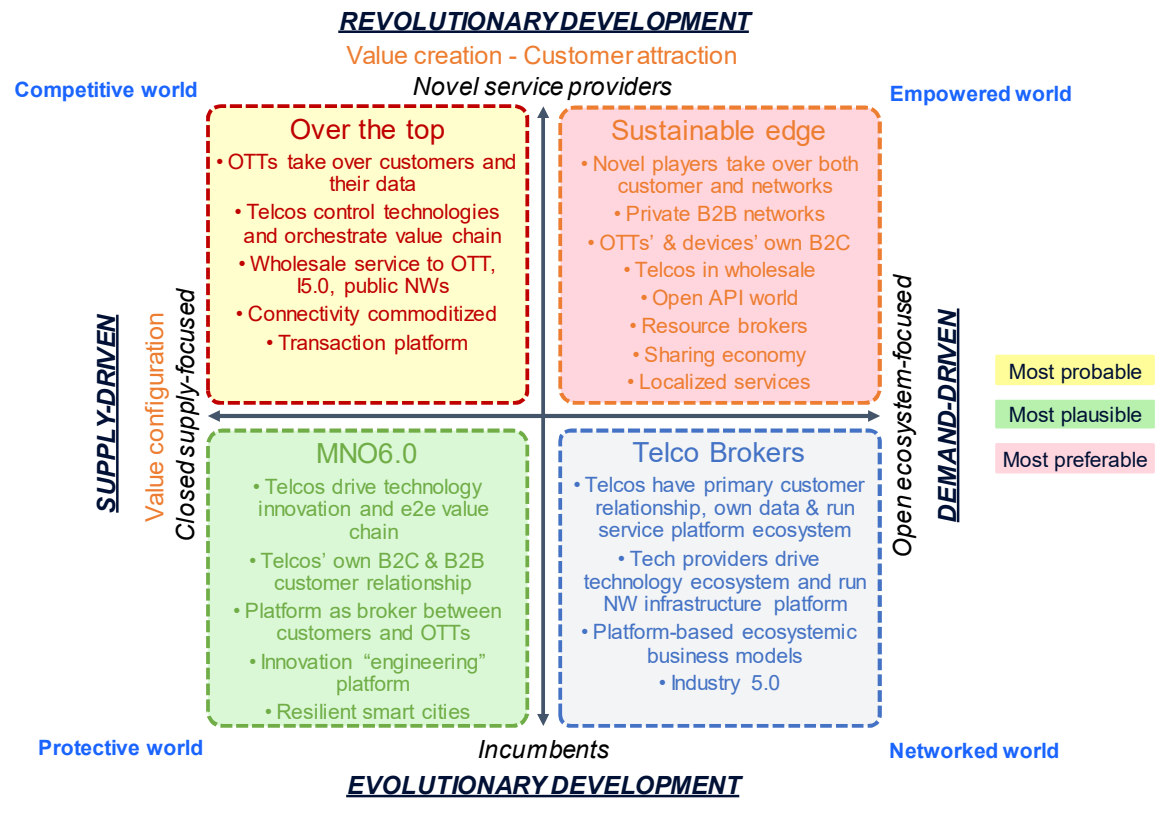

Fig. 4. Summary of developed 6G business scenarios.

In the second scenario, the Telco Broker Value Creation by Incumbents and Open Ecosystem Value Configurations scenario shown in lower-right corner of Figure 4, the main drivers for value creation remain the existing MNOs while value configuration is based on open ecosystem-focus. The MNOs are in charge of customer relationships and use service platform ecosystem to capture value. Technology providers' role is to develop the required technologies and provide network infrastructure via platform-based ecosystemic business models. Innovation ecosystem is broadened by the decoupling of technology platforms. Industry 5.0 (I5.0) has emerged as a key vertical for collaborative human machine interaction with robotization across services and industries. Real-time data and high level of digital automation allow the industries to focus on servitization of products. The speed of operations gets more and more rapid within the increasingly 
reprogrammable and reconfigurable world where design focus gets more and more short-term.

In the third scenario, the MNO6.0 Value Creation scenario shown in the lower-left corner of Figure 4, value creation is driven by the incumbent MNOs, and value configuration is closed supply-focused. The role of MNOs is strong, and they drive technological innovation and own the customer relationships. The existing dominant MNO market position with strong customer base acts as the opportunity for businesses is and the focus is on how to cost-efficiently increase the capacity to meet the growing demand. Technology developments on dynamic networks slicing allowing increasing flexibility, shorter time-to-market, and cost optimization. With the MNO market dominance, the use of $6 \mathrm{G}$ in verticals is heavily dependent on MNOs' business decisions. Key technology developments in the form of automated network slicing and operations in higher frequency bands and new machine learning inspired tools will be used to optimize network operations in a predictive manner allowing new applications. These networks will have been assembled with a public-private-partnership funding model, with a view to resiliency and sustainability.

In the fourth scenario, the Over-the-Top Value Creation scenario shown in upperleft corner of Figure 4, value creation is customer attraction- and lock-in-driven, and value configuration is closed supply-focused. The MNO dominance is replaced by OTTs that have taken over the customer relationships with the help of their access to customer data. The role of operators is to control the standardized and commoditized connectivity technologies and manage the value chains. The role of edge computing is to act as a new control point for serving of the verticals. Networks are programmable and make use of digital twins that represent replicas of complex physical systems to help in optimizing these systems. The ecosystem gets increasingly complicated with different resources and assets needed to meet the versatile needs are brought together by a set of stakeholders including physical infrastructure providers, equipment providers, and data providers under a complex regulatory framework defined by policymakers. Countries with more permitting rules act as resource pools and offer cheap labor, natural resources, and data.

The four developed scenarios were then assessed in terms of their probability, plausibility and preferability. Both the most probable scenario was the Over-the-top scenario while the most plausible scenario was the MNO6.0 scenario. The most preferable scenarios was the Sustainable edge scenario that can be seen to take a bold step towards achievement of the UN SDGS, representing revolutionary and demand-driven transformations.

The developed business scenarios for $6 \mathrm{G}$ indicate that from economic perspective, user experiences will be increasingly local and customized, delivered by local supply models supporting spatial circular economies. New societal service delivery models will appear through community-driven networks and public private partnerships and the role of $6 \mathrm{G}$ will be substantial in vertical industries. The developed scenarios revealed interesting societal observations including increasing tensions between competitive, protective, networked and empowered worldviews. The role of power configurations keeps increasing and may shift from a multi-polarized world to a poly-nodal world. 
The pressure on companies and governments to meet the UN SDGs is evident in the business scenarios for $6 \mathrm{G}$ and the role of $6 \mathrm{G}$ as a provider of services towards environmental impact will be important. 6G with a set of new technologies will help in the monitoring and steering of circular economy to promote a truly sustainable data economy. The developed scenarios also show that $6 \mathrm{G}$ development faces privacy and security issues related to business and regulation including different aims of governance either stemming from governmental, company or end user perspectives. There the ecosystem-level configurations related to users, decentralized and community-driven business models and platforms and related user empowerment become increasingly important to support the role of local $6 \mathrm{G}$ services.

\subsection{Strategic Options for $6 \mathrm{G}$ as Simple Rules}

Next, we summarize the developed strategic options for selected two scenarios using the simple rules framework from [Eisenhardt \& Sull, 2001] that was applied to characterize MNOs' strategic choices in [Ahokangas et al., 2013]. For the most plausible MNO 6.0 scenario, the baseline for building the simple rules is in the use of MNOs' wide existing customer base that has growing capacity needs through investments to strengthen customer lock-in and dominant market position in connectivity, enhanced with customer data and holding on to spectrum. The goal is to maintain dominant market position through gaining access to a new wideband spectrum. Automation of network operations and the ability to dynamically create large numbers of networks slices on-demand will help to increase flexibility, shorten time-to-market, and optimize costs. Resources and services will be traded in automated marketplaces. The MNOs could become a wholesale platform provider for other operators which would further strengthen their market position. Regulations plays a key role in maintaining the MNO market dominance which calls for close contact with the regulator. In the MNO6.0 scenario, the MNOs would never give up on their spectrum and customer data.

For the most preferred Sustainable Edge Scenario, the simple rules are built on the use of new, local, and specialized demand, challenging incumbent MNOs in narrow business segments specializing in governmental, municipal, vertical, or enterprise customers and vertical differentiation with increasing requirements for sustainability in specific industry segments like education, healthcare, and manufacturing. These challenger operators think and act locally, close to the customer and promote resource sharing in different format such as spectrum and virtualized cloud infrastructures. Sustainability requirements in verticals are a major business opportunity through providing vertical differentiation in specific segments like education, healthcare, manufacturing, energy, and media and entertainment. The sustainable edge service provider supports circular economy and promotes sharing economy principles in network deployment. These locally operated networks have opportunities to scale up from local operations to a multi-locality business. Local and private networks provide several benefits in terms of security and data control, separation from public networks, access to highquality services in specific locations, increased flexibility, scalability and customization, and trustworthy reliabilities and latencies. Furthermore, networks can be deployed as standalone sub-networks or integrated with MNO networks. This requires the 
establishment of multi-sided platforms -based regulations to govern privacy and security of users.

\section{$5 \quad$ Future Outlook and Conclusions}

Mobile communication research is increasingly addressing the use of $5 \mathrm{G}$ in verticals, which has led to the emergence of local $5 \mathrm{G}$ network deployment models. Research on $6 \mathrm{G}$ has also started, with a bold goal of building a strong linkage with the United Nations Sustainable Development Goals (UN SDGs). These developments call for a highly multi-disciplinary approach covering business, regulation and technology perspectives and our research is addressing these interrelated themes. This paper has provided an overview of the recent developments in $5 \mathrm{G}$ in verticals towards the development of sustainable $6 \mathrm{G}$. We have highlighted the importance of the triangle of business - regulation - technology perspectives in the development of new wireless technologies and their deployments and summarized the advancements with a focus on local $5 \mathrm{G}$ networks for serving the verticals' needs towards meeting the sustainable development goals.

From the business perspective, a business model for sustainability can help in describing, analyzing, managing and communicating 1) a company's sustainable value proposition to its customers, and other stakeholders, 2) how it creates and delivers this value, 3 ) and how it captures economic value while maintaining or regenerating natural, social, and economic capital beyond its organizational boundaries. The development of new vertical-specific $5 \mathrm{G}$ business opportunities calls for filling in the requirements of scalability, replicability, and sustainability in a legitimate way in a platform ecosystem of connectivity and data services. Digital convergence across industries and multi-level $6 \mathrm{G}$ platforms and ecosystems will create a complex environment where ecosystemic business models for sustainability and the evolution of related regulations become important. Business ecosystems that aim to bring together stakeholders to solve systemic sustainability problems will require open ecosystem-focused value configuration and decentralized power configuration, focusing on the long tail of specialized user requirements that crosses a variety of industries. Future research prospects are particularly related to the new business ecosystems, ecosystemic business models and changing stakeholder roles that support sustainability.

From the regulation perspective, the serving of different verticals with $5 \mathrm{G}$ and future $6 \mathrm{G}$ networks introduces local and often private wireless networks to complement the current mobile network operators (MNOs). The regulatory environment for $5 \mathrm{G}$ in verticals is very complex encompassing rules from both the electronic communications market as well as specific verticals. Especially, the ways how rights to use radio frequencies are granted is critical for the establishment of local $5 \mathrm{G}$ and $6 \mathrm{G}$ networks. The divergence in spectrum awards between countries is increasing with $5 \mathrm{G}$, directly influencing the business opportunities in those countries. There are research prospects in finding the best practices from the decisions by analyzing their impact.

For the technology perspective, $5 \mathrm{G}$ and future $6 \mathrm{G}$ architecture is expected to bring additional modularity and flexibility for traditional MNOs as well as for new local 
operators in system deployments. Key technologies to enable open general-purpose $6 \mathrm{G}$ architecture include distributed heterogenous cloud-native architecture, localization and decomposition of network functions, software defined networking and network virtualization, among others. A critical aspect for the local private industrial networks is their ability to create customized network slices that allow the delivery of services tailored to specific customer needs with service level agreed performance on demand. The availability of spectrum for serving the verticals and operations in higher carrier frequencies present a major technical deployment challenge. The availability of spectrum for serving the verticals on shared basis is important. New research prospects are especially in the $6 \mathrm{G}$ domain in order to find new indicators for $6 \mathrm{G}$ that take sustainability in to account as well as the new network architecture for $6 \mathrm{G}$ needs.

This study has identified a further need for foresight research that explores the interrelated business - regulation - technology perspectives in the context of $5 \mathrm{G}$ in verticals and on the road to sustainable $6 \mathrm{G}$, with a special focus on how can $6 \mathrm{G}$ become a truly general-purpose technology instead of simply an enabling technology, to support countries and organizations in the journey towards the achievement of the UN SDGs. Especially, the verticals burdened by increasing requirements for sustainability will be in the key position in to realize the benefits of using the new technologies.

\section{References}

1. 6G Flagship. White Papers. Available online: https://www.6gchannel.com/6g-white-papers/ (accessed on 24072020) (2020).

2. Ahokangas, P., Matinmikko, M., Yrjölä, S., Okkonen, H., Casey T. "Simple rules" for mobile network operators' strategic choices in future cognitive spectrum sharing networks. IEEE Wireless Communications 20(2), 20-26 (2013).

3. Ahokangas, P., Matinmikko-Blue, M., Yrjölä, S., Seppänen, V., Hämmäinen, H., Jurva, R., \& Latva-aho, M. Business models for local 5G micro operators. IEEE Transactions on Cognitive Communications and Networking, 5(3), 730-740 (2019).

4. Ahokangas, P., Yrjölä, S., Matinmikko-Blue, M., Seppänen, V. Transformation towards 6G ecosystem. In: Proceedings of 2nd 6G Wireless Summit, Levi, Finland, (2020a).

5. Ahokangas, P., Matinmikko-Blue, M., Yrjölä, S. \& Hämmäinen, H. Future vertical 5G platform ecosystems: Case study of a $5 \mathrm{G}$ enabled digitalized port stakeholders' new interactions and value configurations. In: Proceedings of International Telecommunications Society online conference, Gothenburg, Sweden (2020b).

6. Aspara, J., Hietanen, J., Tikkanen, H. Business model innovation vs replication: financial performance implications of strategic emphases. Journal of Strategic Marketing, 18(1), 3956 (2010).

7. Basole, R. C., Karla, J. On the evolution of mobile platform ecosystem structure and strategy. Business \& Information Systems Engineering, 3(5), 313 (2011).

8. Biloslavo, R., Bagnoli, C., Massaro, M., Cosentino, A. Business model transformation toward sustainability: the impact of legitimation. Management Decision (2020).

9. Dreborg, K.H. Essence of backcasting. Futures 28(9), 813-828 (1996).

10. Eisenhardt K.M., Sull D.N. Strategy as simple rules. Harvard Business Review 79(1), 107116 (2001). 
11. Evans, S., Vladimirova, D., Holgado, M., van Fossen, K., Yang, M., Silva, E.A., Barlow, C.Y. Business Model Innovation for Sustainability: Towards a Unified Perspective for Creation of Sustainable Business Models. Bus. Strateg. Environ. 26, 597-608 (2017).

12. Iivari, M., Ahokangas, P., Matinmikko-Blue. M., Yrjölä, S. Opening closed business ecosystems boundaries with digital platforms: empirical case of a port. In: Ziouvelou, X. \& McGroarty, F. (Eds.), Emerging Ecosystem-Centric Business Models for Sustainable Value. IGI Global (2020).

13. Kuhlman, T., Farrington, J. What is sustainability? Sustainability 2(11), 3436-3448 (2010).

14. Latva-aho, M., Leppänen, K. (Eds). Key drivers and research challenges for $6 \mathrm{G}$ ubiquitous wireless intelligence. 6G Research Visions 1, University of Oulu, Finland (2019).

15. Lemstra, W. Leadership with $5 \mathrm{G}$ in Europe: Two contrasting images of the future, with policy and regulatory implications. Telecommunications Policy, 42(8), 587-611 (2018).

16. Letaief, K.B., Chen, W., Shi, Y., Zhang, J., Zhang, Y.A. The Roadmap to 6G: AI Empowered Wireless Networks. IEEE Communications Magazine 57(8), 84-90 (2019).

17. Marano, V., Tallman, S., \& Teegen, H. J.. The liability of disruption. Global Strategy Journal, 10(1), 174-209 (2020).

18. Matinmikko, M. Latva-aho, M., Ahokangas, P., Yrjölä, S., Koivumäki. T. Micro operators to boost local service delivery in 5G. Wireless Personal Communications, vol. 95, no. 1, pp. 69-82, May 2017.

19. Matinmikko, M., Latva-aho, M., Ahokangas, P., \& Seppänen, V. On regulations for 5G: Micro licensing for locally operated networks. Telecommunications Policy, 42(8), 622-635 (2018).

20. Matinmikko-Blue, M., Yrjölä, S., Seppänen, V., Ahokangas, P., Hämmäinen, H., \& LatvaAho, M. Analysis of spectrum valuation elements for local 5G networks: Case study of 3.5GHz band. IEEE Transactions on Cognitive Communications and Networking, 5(3), 741753 (2019).

21. Matinmikko-Blue, M., Aalto, S., Asghar, M.I., Berndt, H., Chen, Y., Dixit, S., Jurva, R., Karppinen, P., Kekkonen, M., Kinnula, M., Kostakos, P., Lindberg, J., Mutafungwa, E., Ojutkangas, K., Rossi, E., Yrjölä, S., Öörni, A., (Eds). White Paper on 6G Drivers and the UN SDGs. 6G Research Visions 2, University of Oulu, Finland (2020a).

22. Matinmikko-Blue, M., Yrjölä, S., Ahokangas, P. Spectrum Management in the 6G Era: Role of Regulations and Spectrum Sharing. In: Proceedings of 2nd 6G Wireless Summit, Levi, Finland, (2020b).

23. Morgado, A., Huq, K. M. S., Mumtaz, S., \& Rodriguez, J. A survey of 5G technologies: regulatory, standardization and industrial perspectives. Digital Communications and Networks 4(2), 87-97 (2018).

24. Nielsen, C., \& Lund, M. Building scalable business models. MIT Sloan Management Review, 59(2), 65-69 (2018).

25. Pouttu A. (Ed.). 6G White Paper on Validation and Trials for Verticals towards 2030's. 6G Research Visions 4, University of Oulu, Finland (2020).

26. Pujol, F., Elayoubi, S. E., Markendahl, J., Salahaldin, L. Mobile telecommunications ecosystem evolutions with 5G. Communications \& Strategies, (102), 109 (2016).

27. Saad, W.; Bennis, M.; Chen, M. A Vision of $6 \mathrm{G}$ Wireless Systems: Applications, Trends, Technologies, and Open Research Problems. IEEE Network (2019).

28. Schaltegger, S., Hansen, E.G., Lüdeke-Freund, F. Business models for sustainability: origins, present research, and future avenues. Organization \& Environment, 29(1), 3-10 (2016).

29. Stevenson, T. Anticipatory action learning: conversations about the future. Futures 34, $417-$ 425 (2012)

30. Schoemaker, P. Scenario Planning: A tool for Strategic Thinking. (1995). 
31. Schwartz, P. The Art of the Long View (1991).

32. Stewart, C. Integral scenarios: reframing theory, building from practice. Futures 40, 160172 (2007).

33. Taleb. T, Aguiar, R. L., Yahia, I. G. B., Chatras, B., Christensen, G., Chunduri, U., Clemm, A., Costa, X., Dong, L., Elmirghani, J., Yosuf, B., Foukas, X., Galis, A., Giordani, M., Gurtov, A., Hecker, A., Huang, C.-W., Jacquenet, C., Kellerer, W., .... Zorzi, M. White Paper on 6G Networking. 6G Research Visions 6, University of Oulu, Finland (2020).

34. United Nations. Global indicator framework for the Sustainable Development Goals and targets of the 2030 Agenda for Sustainable Development (2018).

35. Viswanathan, H., Mogensen, P.E. Communications in the 6G Era. IEEE Access 8, 5706357074 (2020).

36. Vuojala, H., Mustonen, M., Chen, X., Kujanpää, K., Ruuska, P., Höyhtyä, M., MatinmikkoBlue, M., Kalliovaara, J., Talmola, P., Nyström, A.-G. Spectrum access options for vertical network service providers in 5G. Telecommunications Policy 44(4), 101903 (2019).

37. Yrjölä, S., Ahokangas, P. \& Matinmikko-Blue, M. (2019). Novel platform ecosystem business models for future wireless communications services and networks. In: Proxceedings of NFF 2019, Vaasa, Finland (2019).

38. Yrjölä, S.; Ahokangas, P.; Matinmikko-Blue, M., Eds. White Paper on Business of 6G. 6G Research Visions, No. 3, University of Oulu, Finland, (2020a). http://urn.fi/urn:isbn:9789526226767

39. Yrjölä, S. How could Blockchain transform $6 \mathrm{G}$ towards open ecosystemic business models? In: Proceedings of IEEE ICC 2020 Workshop on Blockchain for IoT and CPS, Dublin, Ireland, (2020).

40. Yrjölä, S.; Ahokangas, P.; Matinmikko-Blue. Sustainability as a Challenge and Driver for Novel Ecosystemic 6G Business Scenarios. Sustainability (12), 21 (2020b).

41. Ziegler, V., Yrjölä, S. 6G Indicators of Value and Performance. In: Proceedings of 2nd 6G Wireless Summit, Levi, Finland, (2020). 